Article

\title{
Experimental Study on the Heat Transfer Characteristics of the Enhanced Fin-Tube Heat Exchanger Applied a Coiled Turbulator
}

\author{
Sun-Joon Byun ${ }^{1}$, Sang-Jae Lee ${ }^{2}$, Jae-Min Cha ${ }^{2}$, Zhen-Huan Wang ${ }^{2}$ and Young-Chul Kwon ${ }^{3, *}$ \\ 1 Thermal \& Fluid System Group, Korea Institute of Industrial Technology, 89 Yangdaegiro-gil, lpjang- \\ myeon, Seobuk-gu, Cheonan-si, Chungcheongnam-do 31056, Korea; bjky21@korea.ac (S.-J.B.) \\ 2 Department of Mechanical Engineering, Sunmoon University,70 sunmoon-ro 221 beon-gil, Tangjeong- \\ myeon, Asan-si, Chungcheongnam-do 31460, Korea; heattube@sunmoon.ac.kr (S.-J.L.); \\ jaemin-cha@naver.com (J.-M.C.); huan_2014@nate.com (Z.-H.W.) \\ 3 Division of School of Mechanical and ICT Covergence Engineering, Sunmoon University, 70 sunmoon-ro \\ 221 beon-gil, Tangjeong-myeon, Asan-si, Chungcheongnam-do 31460, Korea; \\ yckweon1@sunmoon.ac.kr (Y.-C.K.) \\ * Correspondence: yckweon1@sunmoon.ac.kr; Tel.: +82-41-530-2396
}

\begin{abstract}
This study presents the comparison of heat transfer capacity and pressure drop characteristics between a basic fin-tube heat exchanger and a modified heat exchanger with the structural change of branch tubes and coiled turbulators. All experiments were carried out using an air-enthalpy type calorimeter based on the method described in ASHRAE standards, under the heat exchanger experimental conditions. 14 different kinds of heat exchangers were used for the experiment. Cooling and heating capacities of the turbulator heat exchanger were excellent, compared to the basic one. As the insertion ratio of the coiled turbulator and the number of row increased, the heat transfer performance increased. However, the capacity per unit area was more effective in 4 rows than 6 rows, and the cooling performance of the 6 row turbulator heat exchanger $(100 \%$ turbulator insertion ratio) was down to about $6 \%$ than that of 4 row one. As the water flow rate and the turbulator insertion ratio increased, the pressure drop of the water side increased. This trend was more pronounced in 6 rows. In the cooling condition, the pressure drop on the air side was slightly increased due to the generation of condensed water, but was insignificant under the heating condition. The power consumption of the pump was more affected by the water flow rate than the coiled turbulator. The equivalent hydraulic diameter of a tube by the turbulator was reduced and then the heat transfer performance was improved. Thus, the tube diameter was smaller, the heat flux was better.
\end{abstract}

Keywords: capacity; cooling and heating; fin-tube heat exchanger; pressure drop; turbulator

\section{Introduction}

In the present era, the demand for a pleasant living condition has increased with the advancements in technology. This demand leads to a drastic rise in energy usage, which also brings about an issue of energy resource depletion and environmental damages. These critical issues are currently being addressed through a varying array of approaches. As energy usage increases for both personal and industrial purposes, efforts are being made to increase the energy consumption efficiency in the field of heating, ventilating, and air conditioning (HVAC) systems to minimize its effects on the environment.

A heat exchanger is a device that allows an heat transfer efficient between two fluids. This device is often used in the fields of chemical processing, heating, air purification, oil refineries, waste heat recovery, and manufacturing, among others. Therefore, a heat exchanger with a variety of application types must be developed to comply with the diverse demands. 
The miniaturization of electronic communication and other mechanical devices leads to issues, such as increased heat release rate per unit area and further spatial limitations. Accordingly, various studies on reducing weight and enhancing the heat exchanger performance are being performed to address such issues [1,2]. The heat transfer performance and efficiency can be enhanced by improving the tube and fin structure and further developing the related optimal design principles of the heat exchanger. Fin-tube heat exchangers are often used in industrial boilers, vehicle radiators, and HVAC and cooling systems. Hence, vigorous researches are being conducted to increase the heat exchanger performance.

The heat transfer process in a fin-tube heat exchanger comprises the heat transfer of latent and sensible heat. With the latent heat process, the state of the working fluid changes and the sensible and latent heats coexist. Meanwhile, with the sensible heat process, the state of the working fluid does not change. Considering these processes, the fin-tube heat exchanger form must be redesigned. In a basic fin-tube heat exchanger, many long tube circuits are connected to a multi-branch. Complex branch tubes are often used depending on the use case of the heat exchanger. The heat transfer efficiency is heavily affected by the latent heat transfer performance. Thus, various tube circuits must be implemented along with the tube and the branch tube circuit design for the maximum latent heat transfer performance. However, with the heat exchangers that use the sensible heat process, the tube circuit must be kept short and simple to optimize the performance of the heat exchanger.

Previous studies on the principle heat exchanger characteristics mainly focused on the heat transfer and pressure drop on the air side for fin-tube heat exchangers [1-4]. In the study of Lee and Yun, the mechanics of the fin-tube heat exchangers were categorized and divided into geometric and physical factors. The effects of modifying the shape of the fin and the number of fins per unit length had also been researched [5]. Through an analysis of the various types of fins used in a fin-tube heat exchanger, Yun et al. published a numerical analysis model for fin shape remodeling to enhance the heat exchanger performance [6]. Kang performed a theoretical assessment for the fin analysis of platetype exchanger [7]. Meanwhile, Lee et al. conducted an experimental and numerical research on the shape of the new fin $[8,9]$. Kim et al. also studied the pressure drop characteristics and the correlation between heat transfer and friction in plain fin and tube heat exchangers [10, 11]. Chang et al. investigated the performance of plate fin-oval tube heat changers equipped with vortex generators [12]. Moreover, Jin et al. studied the heat transfer and pressure drop characteristics in the plain fin heat exchangers in efforts to increase the heat transfer performance for fin-tube heat exchangers [13]. The major focus point of these studies was mainly on the fin shape, distance between each fins and rows, and influences of various geometric factors on the heat transfer and pressure drop. Kurtbas et al. [14] studied the effects of propeller-type turbulators located in the inner pipe of co-axial heat exchanger in order to increase heat transfer in concentric double-pipe heat exchanger. Yakut and Sahin [15] performed an experimental study to investigate flow-induced vibration, heat transfer and performance characteristics for coiled wires turbulators. The turbulator heat exchanger used in this study is different from the basic fin-tube heat exchanger because it does not use complex zigzagshaped branch tubes, thereby further simplifying the heat exchanger architecture by using vertical straight U-bend tubes. The turbulator heat exchanger was designed such that the fluid flow passing the heat exchanger on the air side is not influenced. In addition, the coiled turbulator was inserted into the tube to create more turbulence and enhance the heat transfer performance of the heat exchanger. The existing tube structure of the fin-tube heat exchanger was changed to realize this. Moreover, a modified fin-tube heat exchanger that includes the coiled turbulator was developed. The characteristics of the heat transfer performance and the pressure drop were compared through calorimeter experiments. Furthermore, the heat exchanger performance which changed the tube structure of the head part and applied the coiled turbulator was compared with the conventional fintube heat exchanger. An experimental research was conducted to suggest the possible application and development direction for the turbulator heat exchanger. 


\section{Experimental setups and procedure}

\subsection{Subsection}

In this research, standard branch tubes in a basic fin-tube heat exchanger were changed to vertical straight and U-bend ubes. Furthermore, the heat transfer performance of the modified turbulator heat exchanger with a coiled turbulator implemented had been explored. To compare the turbulator heat exchanger with a basic fin-tube heat exchanger, a psychrometric calorimeter (airenthalpy type) and a constant temperature water bath were used. Figure 1 depicts the psychrometric calorimeter and the schematics of the experimental setup.

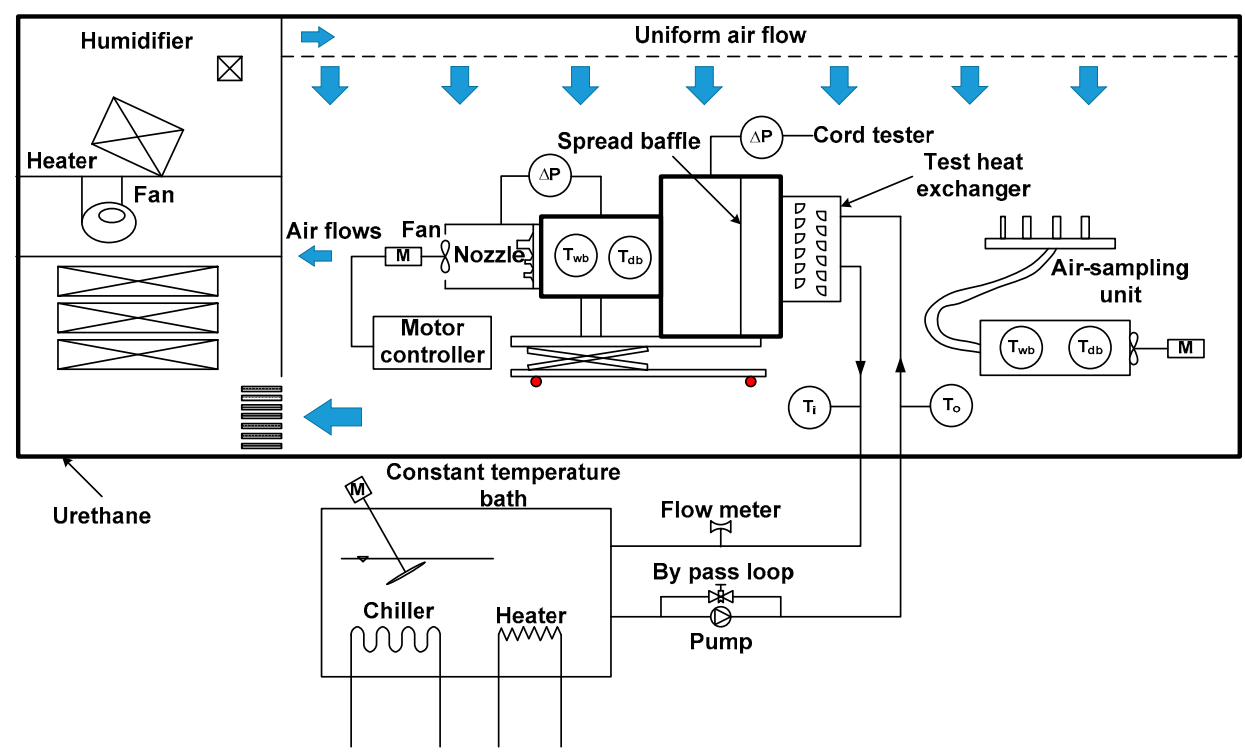

Figure 1. Schematics of the psychrometric calorimeter.

Psychrometric calorimeter is composed of a suction type chamber, constant temperature water bath, air sampling unit, and a data acquisition system. All components other than the constant temperature water bath is situated in the constant temperature and constant humidity chamber. The air flow to the heat exchanger that is installed on the immediate inlet of the constant temperature and humidity chamber is controlled by a HVAC system. The HVAC system, which is set up in the chamber, provides fine control over the inlet air condition (temperature, humidity). The dry/wet temperature of the chamber inlet/outlet is measured by the air sampling unit. The flow rate on the air side is controlled by the suction fan and the subsequent motor controller that resides on the rear end of the chamber. The pressure drop of the air side is measured by the differential pressure nozzle in the chamber. The temperature of the water that flows to the tube in the heat exchanger is controlled and monitored by the chiller and heater PID control within the constant temperature water bath. The dry/wet temperature of the chamber inlet/outlet is measured by the air sampling unit. The flow rate on the air side is controlled by the suction fan and the subsequent motor controller that resides on the rear end of the chamber. The pressure drop of the air side is measured by the differential pressure of nozzle in the chamber. The temperature of the water that flows to the tube in the heat exchanger is controlled and monitored by the chiller and heater PID control within the constant temperature water bath. The error range of the temperature is known to be $\pm 0.3^{\circ} \mathrm{C}$. The flow rate of the water inflow is controlled by varying the rpm of the pump. The inlet/outlet temperature and pressure of the heat exchanger is measured by installing a RTD and a pressure transmitter, and the flow rate is measured by a turbine flow meter (measurement precision of $<0.5 \%$ ). The psychometric calorimeter is designed within the international standards stated in the ASHRAE [16] and the capacity of the air side remains within $\pm 1.0 \%$ deviation at steady state. The reproducibility is within $\pm 0.5 \%$.

In this experiment, the air side condition (dry/wet temperature, flow rate) and the water side condition (flow rate, inlet temperature) of the heat exchanger is first set to compare and analyze the 
heat exchanger performance. Once the air temperature, the air flow rate, the water inlet temperature and the water flow rate reaches stead state, the temperature difference of the water inlet /outlet is monitored until it stabilizes within $\pm 0.2^{\circ} \mathrm{C}$. Then, the flow rate, dry/wet temperature, and pressure difference for air, and the flow rate, the inlet/outlet temperatures of water are measured. Detailed specifications are shown in Table 1. Regarding the experimental conditions of the heat exchanger, the temperature conditions on the air side is controlled by KS C 9306 [17] while the water side uses KS B 6377 [18] to control the temperature condition (cooling and heating).

Figure 2 depicts the schematics of the constant temperature bath and the experimental setup. The constant temperature bath installed on the outside of the constant temperature and constant humidity chamber uses the water as the operated fluid to measure the performance of the heat exchanger. The inlet temperature on the water side is controlled using a PID, which provides accuracy within the range of $\pm 0.3^{\circ} \mathrm{C}$. A $6.0 \mathrm{HP}$ pump is also implemented that allows the maximum water flow rate to be up $50 \mathrm{LPM}$.

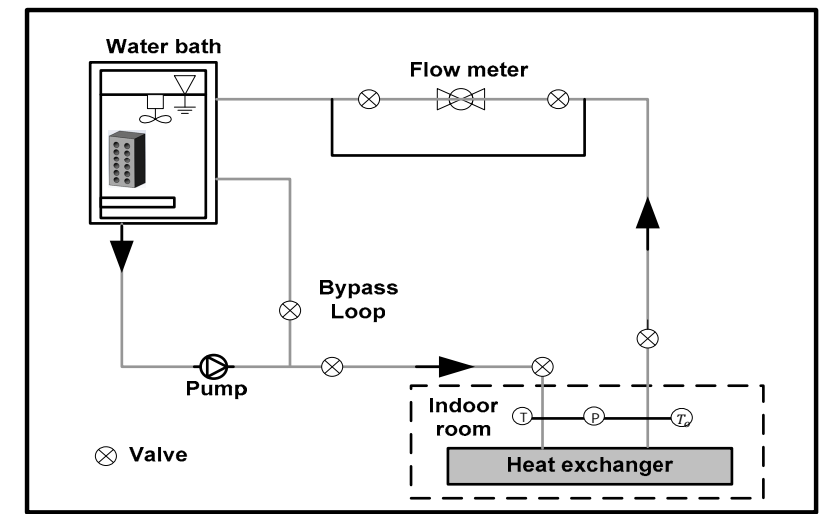

Figure 2. Schematics of the constant temperature bath.

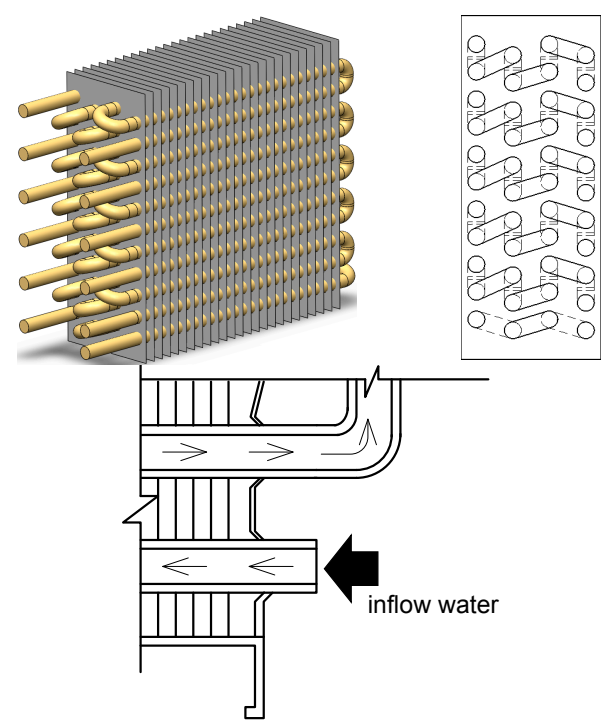

(a)

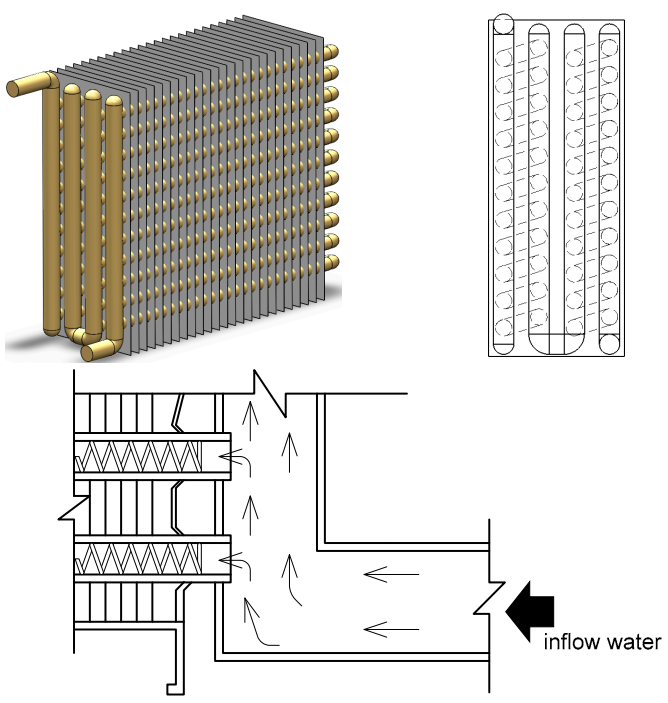

(b)

Figure 3. Schematics of the basic and the turbulator heat exchangers. (a) Basic heat exchanger and tube structure; (b) Coiled turbulator heat exchanger and tube structure.

Figure 3 shows the internal structures of the basic heat exchanger and the turbulator heat exchanger used for the experiment. The turbulator heat exchanger shows similar structure with the exception of the vertical straight tube of the head and the 2 row branch tube structure at the rear end. Also, the heat exchanger performance depending on the existence of a coiled turbulator, which magnifies the turbulence effect of the fluid flow within the tube, is compared. To compare the 
capacity depending on the insertion ratio of the coiled turbulator, experiments are carried out at 0 , 25,50 and $100 \%$ insertion ratios.

In total, 14 different kinds of heat exchangers were used for the experiment, and the details of the basic heat exchanger and the turbulator heat exchanger are listed in Table 2. Furthermore, the heat exchanger performance depending on the existence of a coiled turbulator, which magnifies the turbulence effect of the fluid flow within the tube, were compared.

Table 1. Heat exchanger experimental conditions.

\begin{tabular}{|c|c|c|c|c|}
\hline \multirow[b]{2}{*}{ Item } & \multicolumn{2}{|c|}{ Air side (KS C 9306) } & \multicolumn{2}{|c|}{ Water side (KS B 6377) } \\
\hline & Temperature $\left({ }^{\circ} \mathrm{C}\right)$ & $\begin{array}{l}\text { Flow rate } \\
\left(\mathrm{m}^{3} / \mathrm{min}\right)\end{array}$ & $\begin{array}{c}\text { Inlet } \\
\text { temperature }\left({ }^{\circ} \mathrm{C}\right)\end{array}$ & $\begin{array}{c}\text { Flow rate } \\
(\mathrm{kg} / \mathrm{min})\end{array}$ \\
\hline $\begin{array}{l}\text { Cooling } \\
\text { condition }\end{array}$ & $\begin{array}{l}27.0 \pm 0.3 \text { (dry bulb) } \\
19.5 \pm 0.2 \text { (wet bulb) }\end{array}$ & 2 & $7.0 \pm 0.2$ & $5,10,15,20$ \\
\hline $\begin{array}{l}\text { Heating } \\
\text { condition }\end{array}$ & $\begin{array}{l}18.0 \pm 0.3(\text { dry bulb }) \\
13.0 \pm 0.2 \text { (wet bulb) }\end{array}$ & & $60.0 \pm 0.2$ & $5,10,15,20$ \\
\hline
\end{tabular}

Table 2. Specifications of the basic and the turbulator heat exchangers.

\begin{tabular}{|c|c|c|c|c|c|c|c|c|}
\hline Item & Dimensions & $\begin{array}{c}\text { Front } \\
\text { Area } \\
\left(\mathrm{m}^{2}\right) \\
\end{array}$ & $\begin{array}{c}\text { Fin } \\
\text { pitch } \\
(\mathrm{mm})\end{array}$ & $\begin{array}{l}\text { Fin } \\
\text { type }\end{array}$ & $\begin{array}{l}\text { Number } \\
\text { of rows }\end{array}$ & $\begin{array}{c}\text { Tube } \\
\text { diameter } \\
(\mathrm{mm})\end{array}$ & $\begin{array}{c}\text { Tube } \\
\text { thichness } \\
(\mathrm{mm})\end{array}$ & $\begin{array}{c}\text { Insertion } \\
\text { ratio } \\
(\%) \\
\end{array}$ \\
\hline Basic & $380(\mathrm{~L}) \mathrm{x}$ & & & & & 12.7 & 0.3 & - \\
\hline Turbulator & $\begin{array}{c}420(\mathrm{H}) \mathrm{x} \\
330(\mathrm{D})\end{array}$ & 0.16 & 8 & Slit & 4,6 & 15.9 & 0.4 & $\begin{array}{c}0,25 \\
50,100\end{array}$ \\
\hline
\end{tabular}

Figure 4 shows the shape of the coiled turbulator ( 4 rows, 6 rows) applied in this experiment. The thickness ( $\mathrm{t}$ ) and the pitch $(\mathrm{p})$ of the coil are 1.2 and $8.0 \mathrm{~mm}$. And the diameter $(\mathrm{d})$ of the insert coil is 12.1 and $15.1 \mathrm{~mm}$. Figure 5 depicts the turbulator heat exchanger section of 4 rows and 6 rows depending on the coiled turbulator insertion ratio. With the $0 \%$ coiled turbulator insertion ratio of heat exchanger, only the branch tube shape was changed from the fin-tube heat exchanger. Lastly, depending on the insertion ratio of the coiled turbulator within the tube, the coiled turbulator type were categorized into $0,25,50$ and $100 \%$.
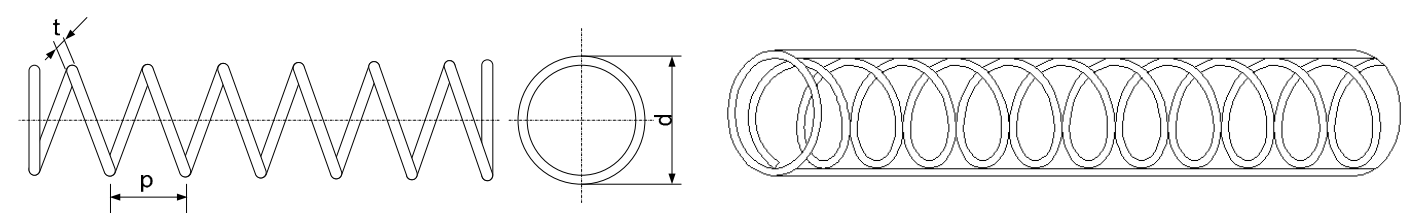

Figure 4. Shape of the coiled turbulator 
Insertion ratio of the coiled turbulator

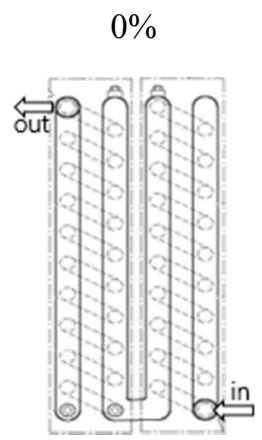

$25 \%$

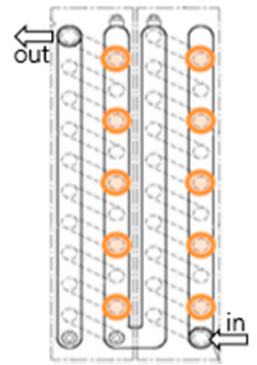

(a)

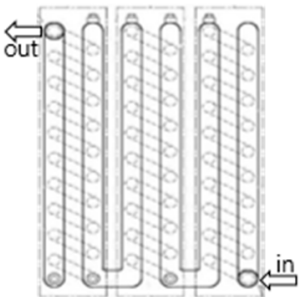

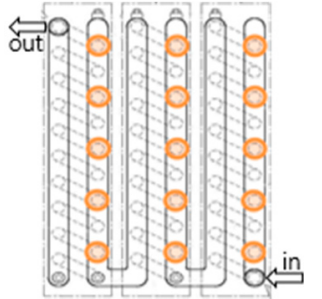

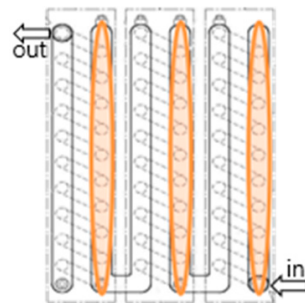

$100 \%$
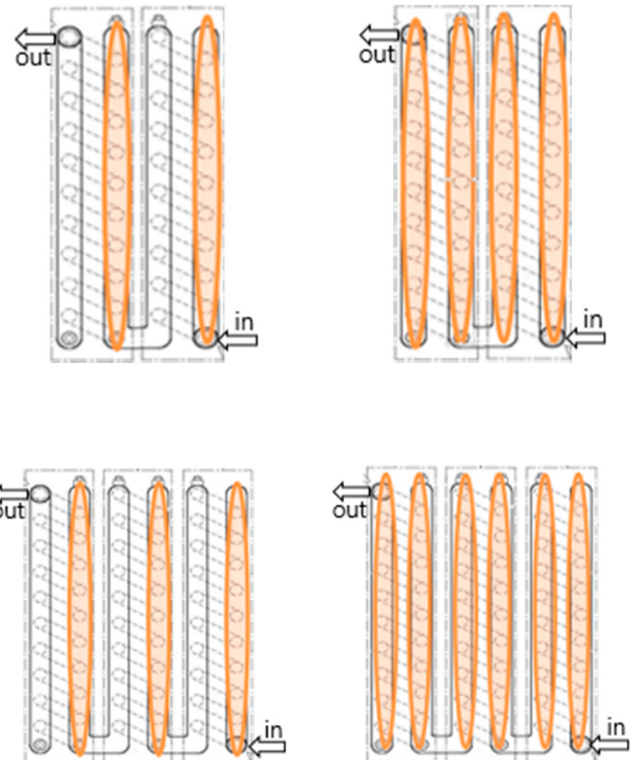

(b)

Figure 5. Schematics of heat exchanger section for the coiled turbulator insertion ratio. (a) 4 rows; (b) 6 rows.

\subsection{Experimental method}

The cooling and heating capacity of the heat exchanger is calculated through the method suggested in KS C 9306 and KS B 6377, which uses the measured air temperature of the inlet and the flow rate and temperature of the outlet. All data signals are collected and transformed using the DAQ system. The DAQ system then converts the signal using GPIB, and sends it to the computer. Once the temperature and flow rate of air and the inlet temperature and air flow rate of water comes to a steady state, and the temperature fluctuation is less than $\pm 0.2^{\circ} \mathrm{C}$. Data such as air flow rate, inlet/outlet dry and wet temperature, pressure difference of air, water flow rate and inlet/outlet temperature is collected in 3 second intervals for 30 minutes. Further calculations are made using arithmetic mean method.

For accurate comparison of the basic fin-tube heat exchanger and the fin-tube heat exchanger with modified tube structure and added turbulator, the specifications of the fins and tubes for all heat exchangers were set to be exactly the same. To address the reliability for the experimental results, the error for the heat balance for air and water side is set to maximum error range of $\pm 4.0 \%$. Furthermore, a wattmeter was used to measure the consumption power of the pump due to the water flow rate of both the basic fin-tube heat exchanger and the turbulator heat exchanger.

\subsection{Data reduction}

The inlet/outlet temperature and the flow rate measured for the air side and the water side were used to obtain the capacity of the air side and the water side using equations (1) and (2). The mean capacity was calculated from the arithmetic average of the capacity of the air side and the water side. The measured values and the fluid properties were used to calculate the capacity of the heat exchanger.

$$
\begin{gathered}
Q_{a}=m_{a}\left(h_{a, i}-h_{a, o}\right) \\
Q_{w}=m_{w} C_{p, w}\left(T_{w, i}-T_{w, o}\right)
\end{gathered}
$$


The inlet/outlet of the water side passes through the air side and the heat exchanger tube, which passes through the front area of the heat exchanger. The pressure difference was determined by measuring the inlet/outlet pressure of the water side. Equations (3) and (4) were used to calculate the value.

$$
\begin{gathered}
\Delta P_{a}=P_{a, i}-P_{a, o} \\
\Delta P_{w}=P_{w, i}-P_{w, o}
\end{gathered}
$$

To secure the reliability for this experiment, the following heat balance was used for the measured capacity of the air and the water side.

$$
\text { Heat balance }(\%)=\frac{Q_{a}-Q_{w}}{Q_{a}} \times 100
$$

In this section, $Q, m, h, C$, and $T$ represents the capacity, mass flow rate, enthalpy, specific heat and temperature, respectively. The subscripts $a, w, i, o$ and $p$ indicates air, water, inlet, outlet and static pressure.

\section{Results and Discussion}

Figure 6 shows cooling capacities on 4 row and 6 row basic and coiled turbulator heat exchangers according to the change in water flow rates. In the case of the 4 row heat exchanger, cooling capacities of the basic heat exchanger were about 2,193 to 4,772 W and those of the coiled turbulator heat exchanger with $0 \%$ turbulator insertion ratio were about 2,334 to $5,077 \mathrm{~W}$, at water flow rates of 5 to $20 \mathrm{~kg} / \mathrm{min}$. On the other hand, cooling capacities of the turbulator heat exchanger $(0,25,50$ and $100 \%$ turbulator insertion ratio) were improved by about $6.4,13.5,24.8$ and $41.0 \%$, respectively, compared with the basic heat exchanger, at the water flow rate of $20 \mathrm{~kg} / \mathrm{min}$. At the same water flow rate, the cooling capacity of the turbulator heat exchanger is improved more than that of the basic heat exchanger because of the arrangement structure of branch tubes and the turbulence effect due to the coiled turbulator inserted in tubes.

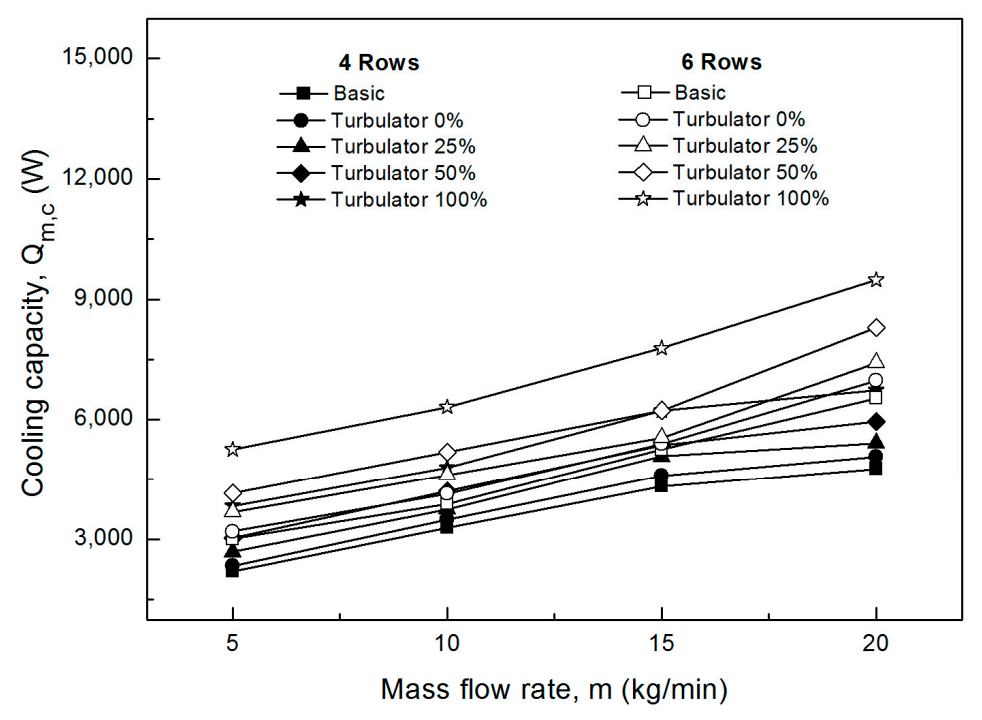

Figure 6. Cooling capacities on the heat exchanger for water flow rate.

In the case of the 6 row heat exchanger, also, cooling capacities of the basic heat exchanger were about 3,005 to $6,538 \mathrm{~W}$ and the those of the turbulator heat exchanger $(0 \%$ turbulator insertion ratio) were 3,197 to $6,976 \mathrm{~W}$, at water flow rates of 5 to $20 \mathrm{~kg} / \mathrm{min}$. Comparing the cooling capacity of the 
basic heat exchanger and the turbulator heat exchanger, those of the turbulator heat exchanger $(0,25$, 50 and $100 \%$ turbulator insertion ratio) were improved by about $6.7,13.5,26.9$ and $44.9 \%$, compared with the basic heat exchanger, at the water flow rate of $20 \mathrm{~kg} / \mathrm{min}$. Comparing these results with the cooling capacity of the turbulator heat exchanger, cooling capacity of the 6 row turbulator heat exchanger is about $40.8 \%$ higher than that of the 4 row heat exchanger. And as the insertion rate of the coiled turbulator increases, the improvement of the cooling capacity is larger. This is due to the heat transfer augmentation by the turbulent flow caused by the coiled turbulator inserted in tubes and the increase in the heat transfer effect by the sensible heat and latent heat between the inflow moist air and the heat exchanger.

Figure 7 shows heating capacities of 4 row and 6 row basic heat exchangers and turbulator heat exchangers according to water flow rates. Heating capacities of the 4 types of the turbulator heat exchanger $(0,25,50$ and $100 \%$ turbulator insertion ratio) were compared with those of the basic heat exchanger in water flow rates of 5 to $20 \mathrm{~kg} / \mathrm{min}$. As the water flow rate increased, the heating capacity was improved. Heating capacities of the 4 row basic heat exchanger were about 5,751 to 7,891 W and those of the 4 row turbulator heat exchanger with $0 \%$ turbulator insertion ratio were about 5,990 to $8,220 \mathrm{~W}$, at water flow rates of 5 to $20 \mathrm{~kg} / \mathrm{min}$. Also, the heating capacity of the 6 row basic heat exchanger were about 8,663 to $11,183 \mathrm{~W}$ and those of the 6 row turbulator heat exchanger $(0 \%$ turbulator insertion ratio) were about 9,024 to $11,649 \mathrm{~W}$, at the same water flow rate. Based on the 4 row basic heat exchanger, at the water flow rate of $20 \mathrm{~kg} / \mathrm{min}$, the heating capacity of the 6 row basic heat exchanger increased by about $41.7 \%$. Those of 4 row and 6 row turbulator heat exchangers $(0 \%$ turbulator insertion ratio) were improved by about 4.2 and $47.6 \%$, respectively. At the same water flow rate $(20 \mathrm{~kg} / \mathrm{min})$, the heating capacity improvement of the turbulator heat exchanger $(50 \%$ turbulator insertion ratio) increased by about $12.5 \%$ at the 4 row basic heat exchanger and by about $60.6 \%$ at the 6 row one. This means that the heat transfer performance of the heat exchanger is improved applying the coiled turbulator to the basic heat exchanger. As can be seen from the experimental conditions, the heating capacity is greater than the cooling capacity (Figure 6). This is because the difference in temperature between water and the inflow air is greater than about $20^{\circ} \mathrm{C}$ under the heating condition. That is, the larger the temperature difference between two fluids is, the better the heat exchange ability is.

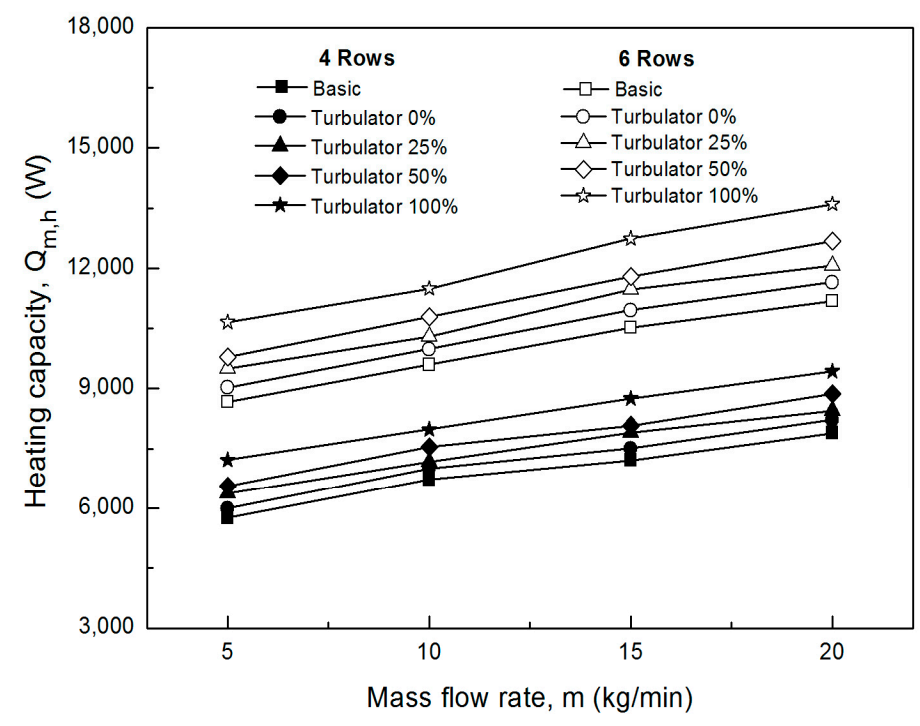

Figure 7. Heating capacities on the heat exchanger for water flow rate.

Figure 8 shows pressure drops of 4 and 6 row basic and turbulator heat exchangers and consumption powers of the pump. At water flow rates of 5 to $20 \mathrm{~kg} / \mathrm{min}$, in the case of the 4 row heat exchanger (Figure 8 (a)), pressure drops of the basic heat exchanger were about 0 to $2.8 \mathrm{kPa}$ and those 


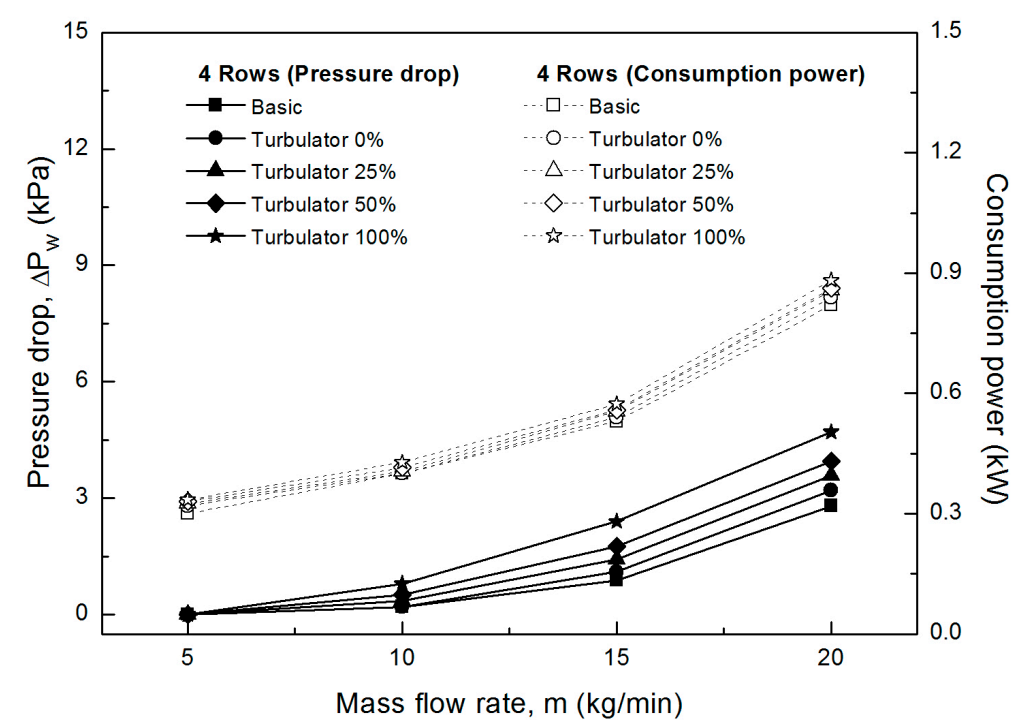

(a)

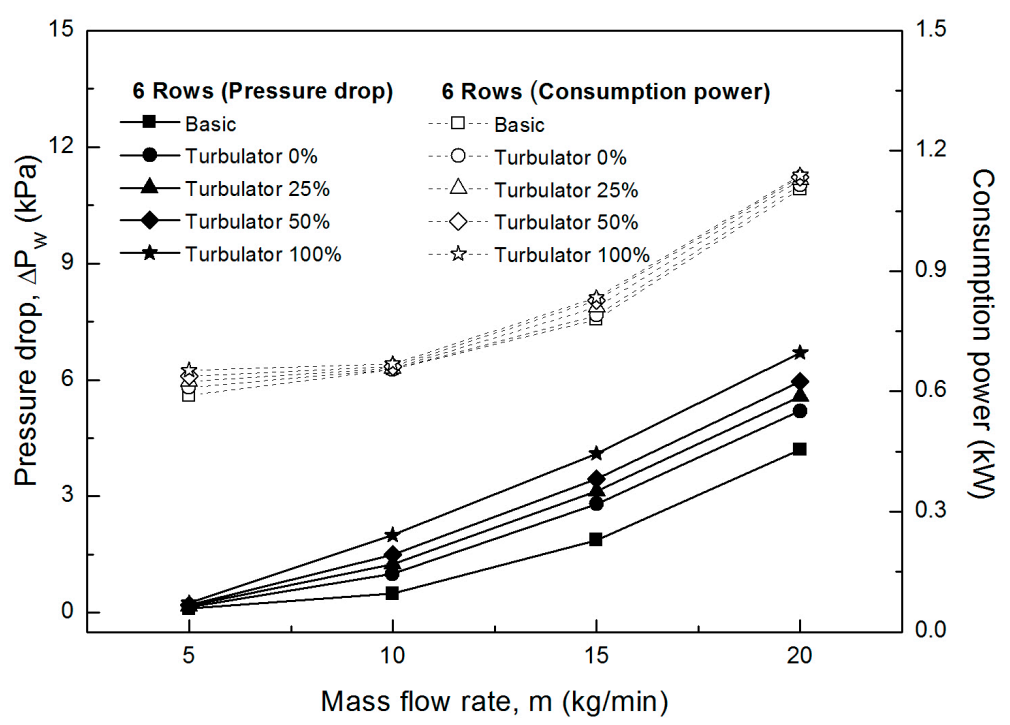

(b)

Figure 8. Pressure drops of the water side and consumption powers for water flow rate. (a) 4 rows; (b) 6 rows.

of the turbulator heat exchanger were about 0 to $3.2,0$ to $3.5,0$ to 3.80 and 0 to $4.72 \mathrm{kPa}$, respectively. The consumption power increased from about 0.30 to $0.88 \mathrm{~kW}$ in the experimental ranges of water flow rate. In the case of the 6 row heat exchanger (Figure 8 (b)), pressure drops of the basic heat exchanger were about 0.1 to $4.2 \mathrm{kPa}$ and those of the turbulator heat exchanger were about 0.15 to 5.2 , 0.2 to $5.6,0.2$ to 6.1 and 0.25 to $6.7 \mathrm{kPa}$, respectively. The consumption power increased from about 0.59 to $1.14 \mathrm{~kW}$ in the experimental ranges of water flow rate. From these results, it can be seen that the increase in the pressure drop is larger, as the turbulator insertion rate and the water flow rate increase. This trend is more pronounced in the 6 rows. Consumption powers of the 6 row heat exchanger were about 29.5 to $96.7 \%$ higher than those of the 4 row heat exchanger, which were more influenced by the change in the water flow rate than the turbulator insertion ratio. 
Figure 9 shows pressure drops of the air side on the basic and turbulator heat exchangers under cooling conditions. Pressure drops of the air side on 4 row basic and turbulator heat exchangers were about 0.06 to $0.08 \mathrm{kPa}$ but the fluctuation width on the water flow rate change did not appear much. However, pressure drops of the air side on the turbulator heat exchanger were larger than that of the basic one. At the same water flow rate, the pressure drop increased as the insertion rate of the coiled turbulator increased. Under cooling conditions, condensed water can easily be generated on the surface of the fin-tube heat exchanger. If the convective heat transfer performance in the tube is increased by the coiled turbulator inserted in tubes, the amount of condensed water generated on the surface of the fin-tube heat exchanger is increased, and as a result, the inflow moist air flowing through the heat exchanger is disturbed and the fluid flow around the tube bundle is changed. Pressure drops of the 6 row heat exchanger showed a similar tendency to those of the 4 row heat exchanger, at water flow rates of 5 to $20 \mathrm{~kg} / \mathrm{min}$. At the turbulator insertion rates of $0,25,50$ and $100 \%$, pressure drops of the air side were increased to about 0.1 to $0.15 \mathrm{kPa}$ and were slightly larger than those of the 4 row heat exchanger. This is because the heat exchanger area of the air side on the 6 row heat exchanger is increased by about $50 \%$ than that of the 4 row heat exchanger, and the latent heat region at the tube bundle within the heat exchanger is relatively increased. Therefore, condensed water influencing the air flow within the heat exchanger was generated more than the 4 row heat exchanger. Also, as the insertion ratio of the coiled turbulator in tubes increased, the pressure drop of the air side increased somewhat. And condensed water of 4 row and 6 row turbulator heat exchangers increased to about 34 and $42 \%$ respectively, compared with the basic heat exchanger. That is, the increase in the amount of condensed water under the cooling condition indicates that the heat transfer performance due to the increase in the latent heat effect is improved.

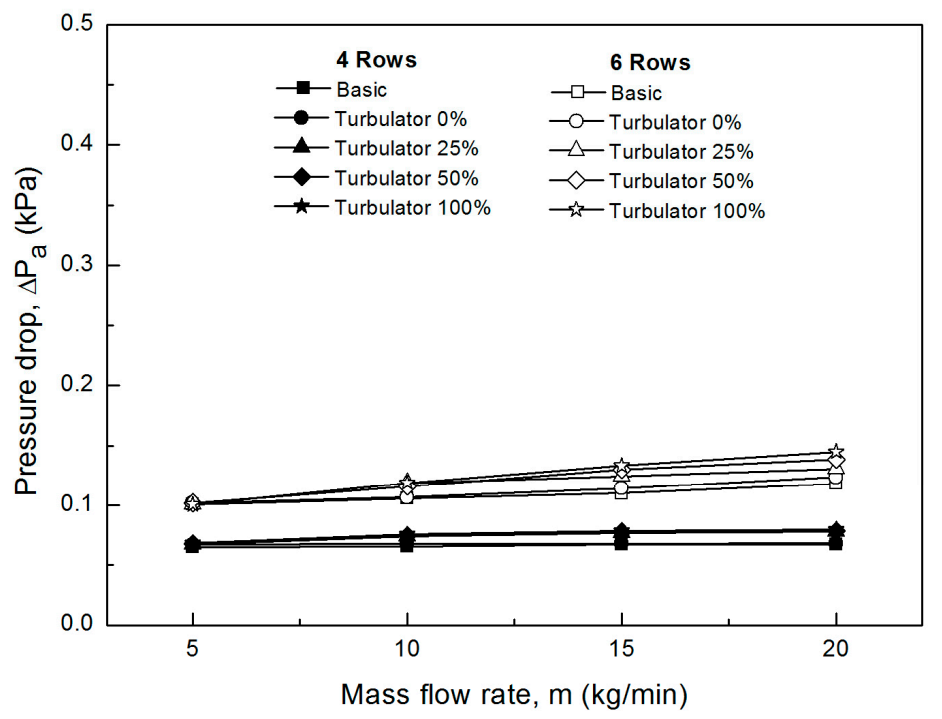

Figure 9. Pressure drops of the air side for water flow rate under the cooling condition.

Figure 10 shows pressure drops of the air side on basic and the turbulator heat exchangers under the heating condition. Pressure drops of the air side under heating conditions were about 0.03 to 0.05 $\mathrm{kPa}$, which were lower than those in cooling conditions. In the case of the 6 row heat exchanger, pressure drops were about 0.08 to $0.10 \mathrm{kPa}$. In addition, the variation of the pressure drop was not significant even when the coiled turbulator insertion ratio increased. Pressure drop of the air side was lower under the heating condition than the cooling one. This is because the surface of the heat exchanger under the cooling condition is in a wet state, but that under the heating condition is in a dry state. That is, condensed water is not generated at the dry surface condition. Under the same cooling and heating conditions, the increase in the pressure drop of the air side on the 6 row heat 
exchanger compared to the 4 row heat exchanger is considered to be due to the pressure loss by the flow friction induced by the increase of the heat transfer area of the air side.

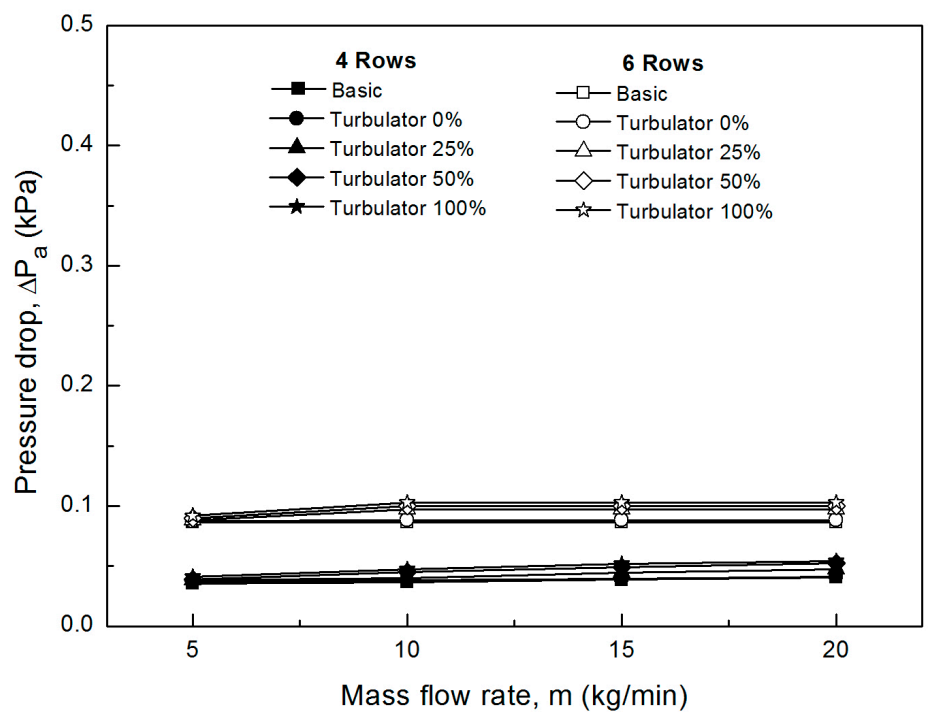

Figure 10. Pressure drops of the air side for water flow rate under the heating condition.

Figure 11 shows cooling heat fluxes (heat transfer rate per unit area) and consumption powers of the pump for outer diameters of 12.7 and $15.9 \mathrm{~mm}$. Figure 11(a) shows that cooling heat fluxes of the 4 row basic heat exchanger and the turbulator heat exchanger (100\% turbulator insertion ratio) with outer diameters of 12.7 and $15.9 \mathrm{~mm}$ are about $322.2,454.5,284.2$ and $400.8 \mathrm{~kW} / \mathrm{m}^{2}$, respectively, at the water flow rate of $20 \mathrm{~kg} / \mathrm{min}$. As the tube diameter decreases, the heat flux is improved. Therefore, when the coiled turbulator is inserted into the tube, the equivalent hydraulic diameter of the heat exchanger is reduced, thereby improving the heat transfer performance. In addition, the heat transfer performance of the turbulator type with the coil inserts than the basic type is more effective due to the enhancement of convective heat transfer by the turbulent generation effect in the tube. The consumption powers of the pump increased as the water flow rate increased, but the change in the tube diameter and the influence on the insertion of the coiled turbulator were insignificant.

Figure 11(b) shows that cooling heat fluxes of the 6 row basic heat exchanger and the turbulator heat exchanger (100\% turbulator insertion ratio) with outer diameters of 12.7 and $15.9 \mathrm{~mm}$ are about $294.3,426.7,261.0$ and $378.3 \mathrm{~kW} / \mathrm{m}^{2}$, respectively, at the water flow rate of $20 \mathrm{~kg} / \mathrm{min}$. Since the heat transfer area of the air side on the 6 row heat exchanger is larger than the 4 row one, the cooling heat flux of the 6 row one is higher than that of the 4 row one. Based on the 4 row basic heat exchanger at the water flow rate of $20 \mathrm{~kg} / \mathrm{min}$, the cooling heat flux of the turbulator heat exchanger $(100 \%$ tubulator insertion ratio) increased by about $41.0 \%$ at the diameter of $12.7 \mathrm{~mm}$ and increased by about $24.3 \%$ at the diameter of $15.9 \mathrm{~mm}$. In case of the 6 row heat exchanger, the cooling heat flux on the turbulator heat exchanger (100\% turbulator insertion ratio) increased by about $44.9 \%$ at the diameter of $12.7 \mathrm{~mm}$ and increased by about $28.5 \%$ at the diameter of $15.9 \mathrm{~mm}$.

Cooling heat fluxes of the 6 row turbulator heat exchanger (100\% turbulator insertion ratio) decreased by about $6.1 \%$ and $5.6 \%$ at diameters of 12.7 and $15.9 \mathrm{~mm}$, respectively, than that of the 4 row one. This shows that the heat transfer rate per unit area can be reduced even if the heat transfer area of the heat exchanger is increased. That is, since the 4 row heat exchanger is superior to the 6 row one, the heat exchanger can be miniaturized. On the other hand, the outlet dry temperature and relative humidity at the air side of the heat exchanger were $14.6{ }^{\circ} \mathrm{C}$ and $76 \%$, and the outlet temperature at the water side was $14.4^{\circ} \mathrm{C}$ for the 6 row heat exchanger $(100 \%$ turbulator insertion ratio), at the water flow rate of $20 \mathrm{~kg} / \mathrm{min}$. This condition is evaluated to be a limitation of effective 
heat transfer, and it is considered that the increase width of the heat transfer will gradually decrease even if the water flow rate is increased.

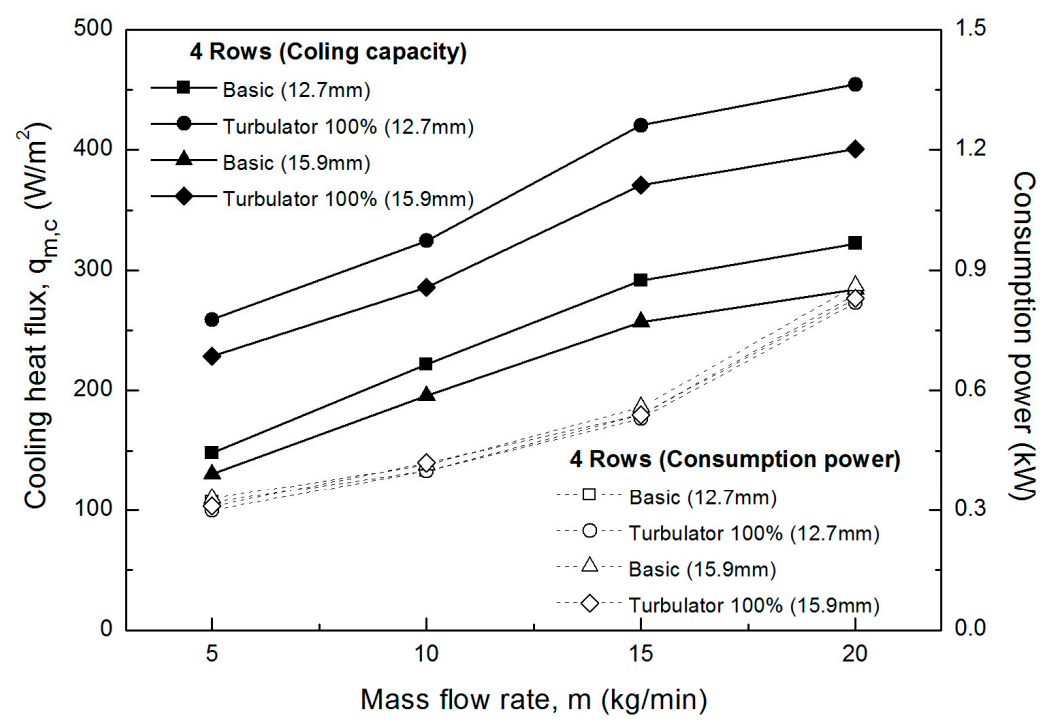

(a)

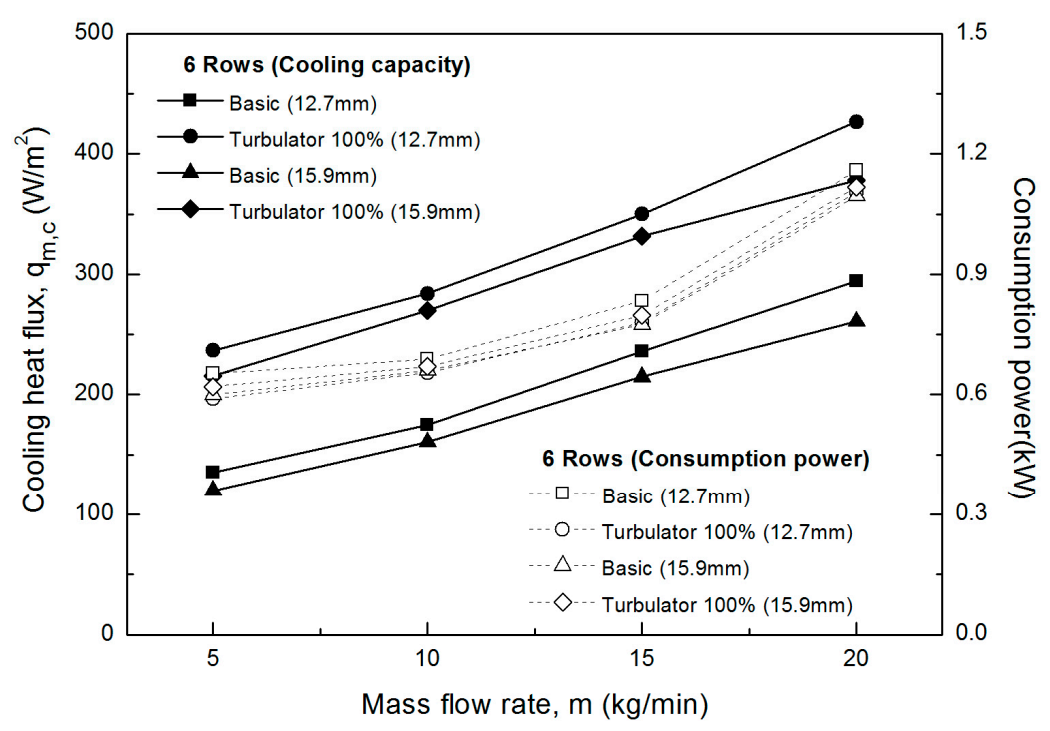

(b)

Figure 11. Cooling heat fluxes and consumption powers for outer diameter. (a) 4 rows; (b) 6 rows.

Figure 12 shows heating heat fluxes and power consumptions of the pump for the outer diameters of 12.7 and $15.9 \mathrm{~mm}$. Figure 12(a) shows that heating heat fluxes of the 4 row basic heat exchanger and the turbulator heat exchanger $(100 \%$ turbulator insertion ratio) with outer diameters of 12.7 and $15.9 \mathrm{~mm}$ are about $532.8,636.8,469.9$ and $561.6 \mathrm{~kW} / \mathrm{m}^{2}$, respectively, at the water flow rate of $20 \mathrm{~kg} / \mathrm{min}$. Results of the heating experiment on the heat flux for tube diameter and the consumption power for the water flow rate showed similar trend to those of the cooling experiment. In the case of the turbulator type with the coil insert, the heat transfer of the heat exchanger was improved due to the turbulence generation and the vortex effect in tubes. 
Figure 12(b) shows heating heat fluxes of the 6 row basic heat exchanger and the turbulator heat exchanger (100\% turbulator insertion ratio) with outer diameters of 12.7 and $15.9 \mathrm{~mm}$ are about 503.3, $612.1,446.3$ and $542.7 \mathrm{~kW} / \mathrm{m}^{2}$, respectively, at the water flow rate of $20 \mathrm{~kg} / \mathrm{min}$. The heat transfer area of the air side on the 6 row heat exchanger is larger than that of the 4 row one. Therefore, the total capacity is large, but the heat flux can be varied. The capacity of the 6 row heat exchanger is excellent in $12.7 \mathrm{~mm}$ outer diameter, but the 4 row heat exchanger is more excellent in $15.9 \mathrm{~mm}$ outer diameter. This is because the heat transfer efficiency is continuously improved with increase in heat transfer area when the heat exchanger is changed from 4 row to 6 row in the case of $12.7 \mathrm{~mm}$ outer diameter. On the other hand, in the case of $15.9 \mathrm{~mm}$ outer diameter, the total capacity increases due to the increase of the heat transfer area, but the heat flux decreases. And then the heat transfer efficiency becomes lower than the area increase ratio on the capacity. That is, the heat flux according to the change in the outer diameter is larger in 6 row than in 4 row, and that decreases as the outer diameter

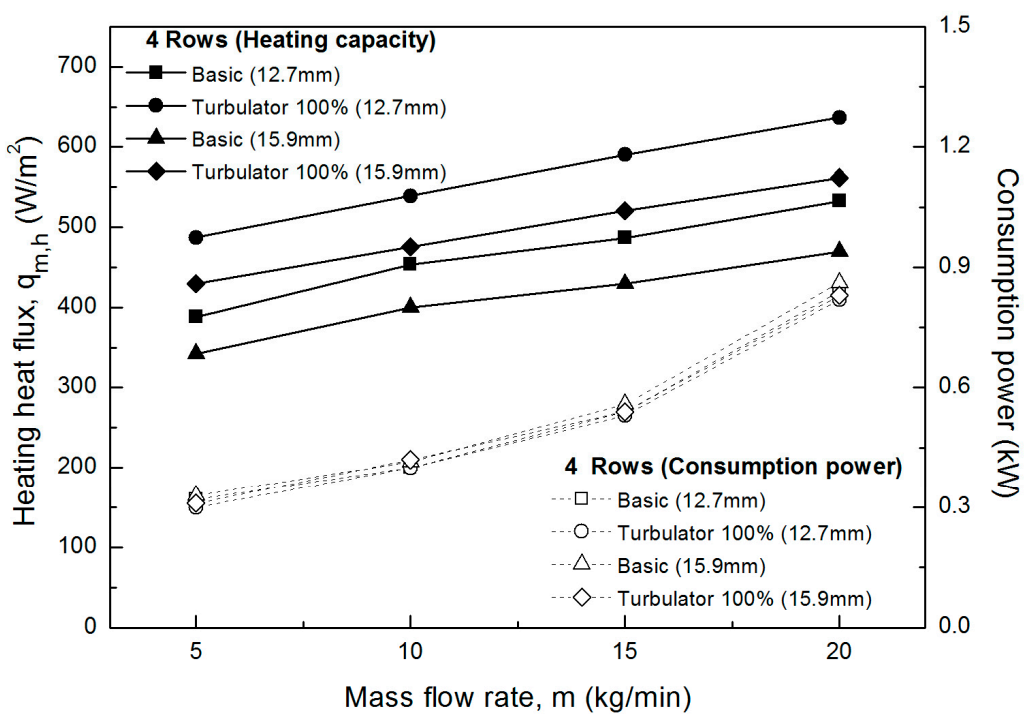

(a)

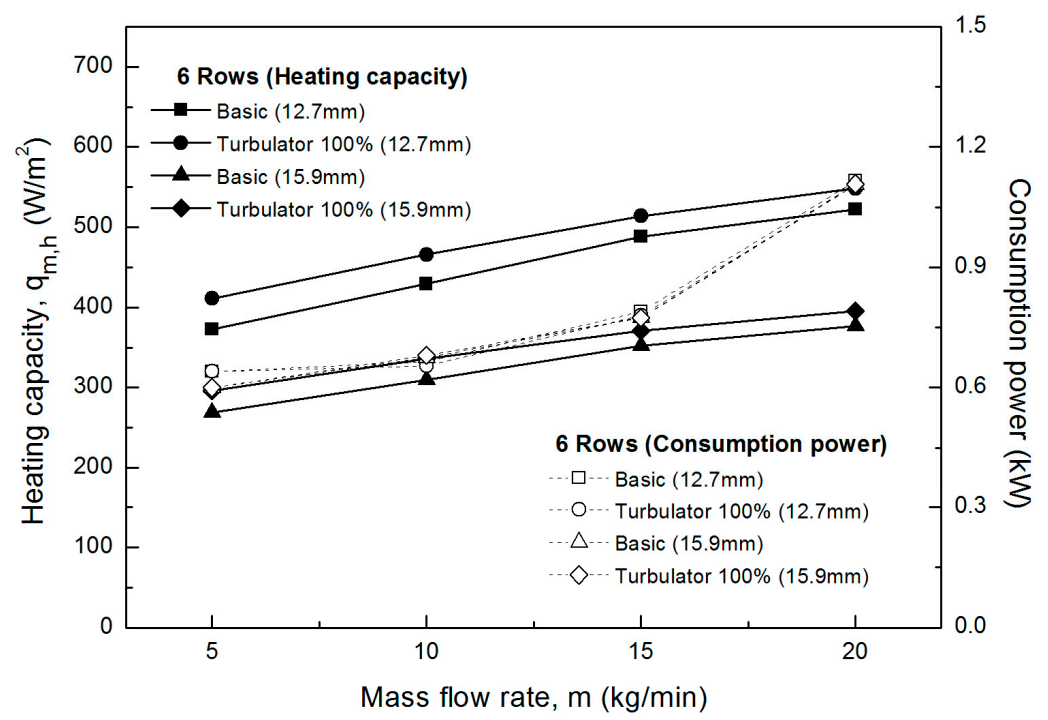

(b)

Figure 12. Heating heat fluxes and consumption powers for outer diameter. (a) 4 rows; (b) 6 rows. 
is larger. Based on the 4 row basic heat exchanger at the water flow rate of $20 \mathrm{~kg} / \mathrm{min}$, the heating heat flux of the turbulator heat exchanger (100\% turbulator insertion ratio) increased by about $19.5 \%$ at the outer diameter of $12.7 \mathrm{~mm}$ and decreased by about $5.4 \%$ at the outer diameter of $15.9 \mathrm{~mm}$. In case of the 6 row heat exchanger, the heating heat flux increased by about $21.6 \%$ at the outer diameter of $12.7 \mathrm{~mm}$ and decreased by about $7.8 \%$ at the outer diameter of $15.9 \mathrm{~mm}$. In results of the heating experiment, the heating heat flux increased almost linearly, but the tendency to slow down the increase in heat flux shown in the cooling experiment above water flow rate of about $15.0 \mathrm{~kg} / \mathrm{min}$ was insignificant.

Figure 13 shows pressure drops of the water side for the outer diameter (12.7 and $15.9 \mathrm{~mm})$ under heating conditions. When the water flow rate is $20 \mathrm{~kg} / \mathrm{min}$, pressure drops of the basic heat exchanger are about 2.8 and $1.98 \mathrm{kPa}$ when those of the turbulator heat exchanger $(100 \%$ turbulator insertion ratio) are about 4.7 and $3.2 \mathrm{kPa}$, respectively. Under the same water flow rate, the pressure

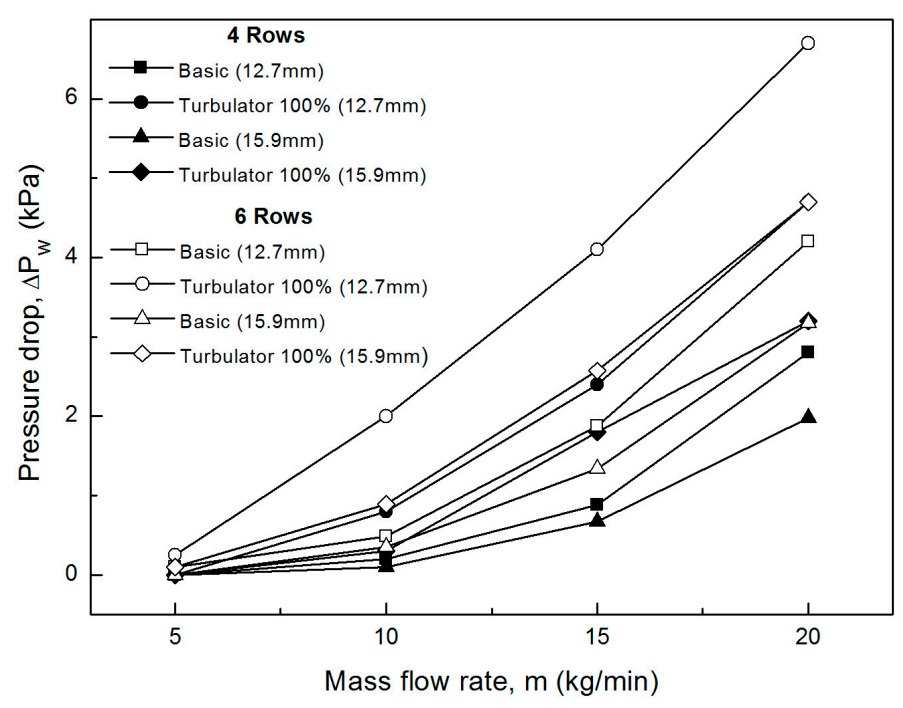

Figure 13. Pressure drops of the water side for the outer diameter under the heating condition.

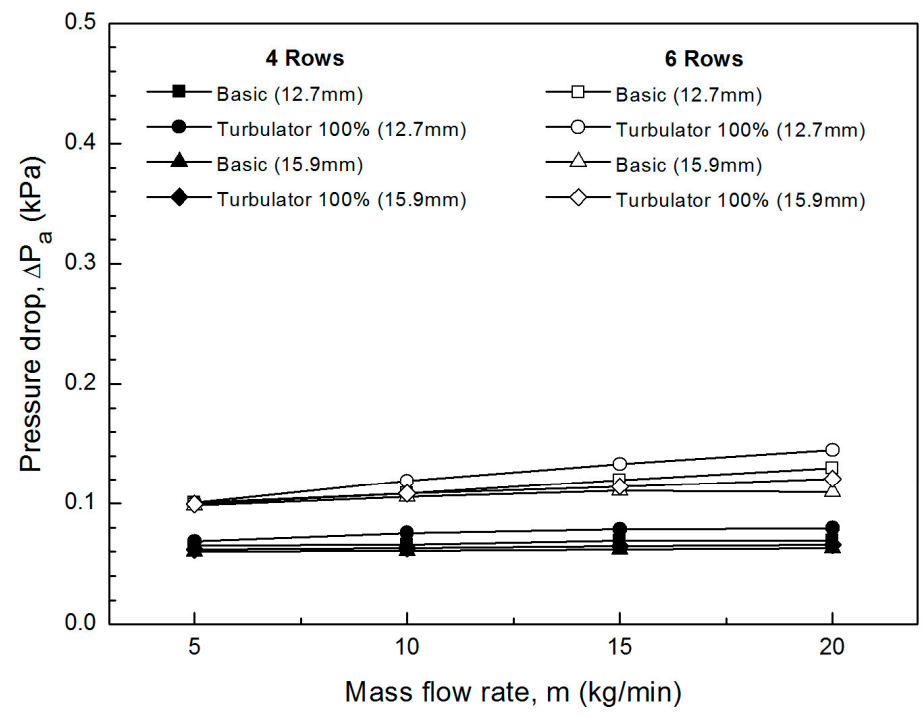

Figure 14. Pressure drops of the water side for the outer diameter under the cooling condition. 
drop increases by the turbulator inserts in tubes, and that decreases when the tube outer diameter is large. From the pressure drop experiments in 4 and 6 rows, the pressure drop increases as the tube outer diameter decreases and the water flow rate increases. And the pressure drop increases linearly with the increase of the water flow rate when the turbulator insertion ratio is $100 \%$. This is because the pressure loss increases due to the increase of the turbulator insertion rate and the flow rate.

Figure 14 shows pressure drops of the air side for the outer diameter $(12.7$ and $15.9 \mathrm{~mm})$ under cooling conditions. When the water flow rate was $20 \mathrm{~kg} / \mathrm{min}$, pressure drops of the 4 row basic heat exchanger were about 0.07 and $0.063 \mathrm{kPa}$ when those of the turbulator heat exchanger $(100 \%$ turbulator insertion ratio) were 0.08 and $0.065 \mathrm{kPa}$, respectively. The changes in the outer diameter and the water flow rate was slightly different, but the pressure drop of air side mass very low compared to the pressure drop of the water side. In the 6 row exchanger, the pressure drop increased as the water flow rate increases. However, the pressure drop due to the variation of the outer diameter and the application of the turbulator was somewhat larger than those of the 4 row heat exchanger.

At the water flow rate of $20 \mathrm{~kg} / \mathrm{min}$, pressure drops of the basic heat exchanger were about 0.13 and $0.11 \mathrm{kPa}$ when those of the turbulator heat exchanger (100\% turbulator insertion ratio) were about 0.15 and $0.12 \mathrm{kPa}$, respectively. The 6 row heat exchanger has a larger heat transfer area than the 4 row heat exchanger, which facilitates condensate generation on the heat exchanger and the tube surface under cooling conditions. It narrows the flow path on the air side of the heat exchanger and interrupts the air flow. As a result, the pressure drop becomes large.

\section{Conclusions}

This paper describes the comparison of heat transfer capacity and pressure drop characteristics between the basic fin-tube heat exchanger and the modified heat exchanger with the structural change of branch tubes and coiled turbulators. The complicated zig-zag branch tubes were not applied and the coiled turbulators inside tubes were inserted. All experiments were carried out using the air-enthalpy type calorimeter. The total 14 experiments were performed for the heat exchanger type (basic, coiled turbulator), the row (4 and 6 rows), the diameter (12.7 and $15.9 \mathrm{~mm})$, the turbulator insertion ratio $(0,25,50$ and $100 \%)$, the water flow rate $(5,10,15$ and $20 \mathrm{~kg} / \mathrm{min})$ and the experimental condition (heating, cooling). The cooling and heating capacity of the heat exchanger is calculated through the method suggested in KS C 9306 and KS B 6377. From the present experimental work, the following conclusions are summarized as follows:

(1) Cooling and heating capacities of the turbulator heat exchanger $(0,25,50$ and $100 \%$ turbulator insertion ratio) were improved by about 6.4 to $41.0 \%$ and about 6.7 to $44.9 \%$ for 4 rows, about 4.2 to $19.5 \%$ and about 4.2 to $21.6 \%$ for 6 rows, compared with the basic heat exchanger. The cooling and heating capacity of the 6 row turbulator heat exchanger were about $40.8 \%$ and about $44.2 \%$ higher than those of the 4 row one at $100 \%$ turbulator insertion ratio. As the insertion ratio of the coiled turbulator and the number of row increased, the heat transfer performance increased.

(2) As the water flow rate and the turbulator insertion ratio increased, the water pressure drop increased. Pressure drops of the turbulator heat exchanger $(0,25,50,100 \%$ turbulator insertion ratio) increased by about 14.3 to $67.9 \%$ for 4 rows, about 23.8 to $59.5 \%$ for 6 rows, compared with the basic heat exchanger. Pressure drop of the turbulator heat exchanger of the 6 rows were about $42.6 \%$ higher than those of the 4 rows at $100 \%$ turbulator insertion ratio. Also, in the cooling condition, the pressure drop on the air side was slightly increased due to the generation of condensed water, but was insignificant under the heating condition. The power consumption was more affected by the water flow rate than the coiled turbulator.

(3) The capacity per unit area was more effective in 4 rows than 6 rows. The cooling heat fluxes of 6 rows (100\% turbulator insertion ratio) were down to about $6.1 \%$ (for $12.7 \mathrm{~mm}$ ) and about $5.6 \%$ (for $15.9 \mathrm{~mm}$ ) than those of 4 rows. The heating heat fluxes of 6 rows (100\% turbulator insertion ratio) 
were down to about $3.9 \%$ (for $12.7 \mathrm{~mm}$ ) and about $3.4 \%$ (for $15.9 \mathrm{~mm}$ ) than those of 4 rows. Also, the pressure drop increases by the turbulator inserts in tubes, and that decreases when the tube outer diameter is large. The tube equivalent hydraulic diameter by coiled turbulators was reduced and then the heat transfer performance was improved.

Acknowledgments: This work was supported by the Sun Moon University Research Grant of 2015.

\section{Nomenclature}

$C_{p} \quad$ specific heat $(\mathrm{J} / \mathrm{kg} \cdot \mathrm{K})$

$h$ convective heat transfer coefficient $\left(\mathrm{W} / \mathrm{m}^{2} \cdot \mathrm{K}\right)$

$m$ mass flow rate $(\mathrm{kg} / \mathrm{min})$

$P$ pressure $(\mathrm{kPa})$

$\triangle P$ pressure drop $(\mathrm{kPa})$

$q$ heat flux $\left(\mathrm{W} / \mathrm{m}^{2}\right)$

$Q \operatorname{capacity}(\mathrm{W})$

$T$ temperature $\left({ }^{\circ} \mathrm{C}\right)$

\section{Subscripts \\ a air \\ c cooling \\ $h$ heating \\ $i \quad$ inlet \\ o outlet \\ $m$ mean \\ $w$ water}

\section{References}

1. Wang, C.C.; Tao, W.H.; Chang, C.J. An investigation of the air side performance of the slit fin-and-tube heat exchangers, Int. J. Refrig. 1999, 22, 595-603.

2. Du, Y.J.; Wang, C.C. An experimental study of the air-side performance of the super slit fin-and-tube heat exchangers, Int. J. Heat Mass Transf. 2000, 43, 4475-4482.

3. Wang, C.C.; Lee, W.S.; Sheu, W.J. A comparative study of compact enhanced fin-and-tube heat exchangers, Int. J. Heat Mass Transf. 2001, 44, 3565-3573.

4. Dejong, N.C.; Jacobi, A.M. An experimental study of flow and heat transfer in parallel-plate arrays: local, row-by-row and surface average behavior, Int. J. Heat Mass Transf. 1997, 40, 1365-1378.

5. Lee, J.D.; Yun, J.Y. Research review for parametric characteristics on heat exchanger, Trans. Korean Soc. Mech. Eng. 1993, 33, 1, 936-941.

6. Yun, J.W.; Yun, J.Y.; Kim, M. Numerical study on the characteristics of flow an heat transfer in finned tube heat exchanger, Trans. Soc. Air-Con. Refrig. Eng. 1996, 25(2), 137-150.

7. Kang, H.C. Fin efficiency of the heat exchanger, Trans. Soc. Air-Con. Refrig. Eng. 1999, 1151-1121.

8. Lee, M.K.; Chang, K.S.; Kweon, Y.C.; Yun, J.W. Development on new fin of fin-tube heat exchanger for A/C system, Proc. Soc. Air-Con. Refrig. Eng. 2002, 153-158.

9. Lee, J.H.; Lim, M.K; Kang, H.C. Forced convection characteristics of V type circular-finned tube heat exchanger, Proc. Soc. Air-Con. Refrig. Eng. 2009, 1348-1354.

10. Kim, N.H.; Youn, B.; Webb, R.L. Heat transfer and friction correlations for plain fin and tube heat exchangers, Proc. 11th Int. Heat Transf. Conf. 1998, 6, 209-213.

11. Kim, N.H.; Cho, J.P.; Choi, Y.H.; Ku, H.G. Heat transfer and pressure drop characteristics of plain finned heat exchangers having $5.0 \mathrm{~mm}$ tubes, Trans. Soc. Air-Con. Refrig. Eng. 2008, 16(1), 9-14. 
12. Chang, H.S.; Chun, Y.W.; Chung, I.K. Study on performance of plate fin-oval tube heat exchanger with vortex generators, Proc. Korean Soc. Mech. Eng. 2005, 345-350.

13. Jin, D.H.; Na, B.; Jang, D.Y.; Yun, J.Y. Study on the heat transfer and pressure drop characteristics in the plain fin heat exchangers with round tube, Proc. Soc. Air-Con. Refrig. Eng. 1999, 306-309.

14. Kurtbaș, İ.; Durmus, A.; Eren, H.; Turgut, E. Effect of propeller type swirl generators on the entropy generation and efficiency of heat exchangers, Int. J. Thermal Sciences 2007, 46, 300-307.

15. Yakut, K.; Sahin, B. The effects of vortex characteristics on performance of coiled wire turbulators used for heat transfer augmentation, Appl. Eng. 2004, 24, 2427-2438.

16. ASHRAE Standard, Methods of testing forced circulation air cooling and air heating coils, 1978, 33-78.

17. Korean Standard Association, KS Air conditioner: KS C 9306, 2007.

18. Korean Standard Association, KS Fan coil units: KS B 6377, 2009.

(C) 2017 by the authors; licensee Preprints, Basel, Switzerland. This article is an open access article distributed under the terms and conditions of the Creative Commons by Attribution (CC-BY) license (http://creativecommons.org/licenses/by/4.0/). 